\title{
Whose Rules Rule? \\ Development and the Global Governance of Biotechnology
}

Peter Newell and Ruth Mackenzie*

\section{Introduction}

Few case studies highlight as clearly the intersection of globalisation with poverty as the role of biotechnology in the developing world. The "gene" revolution in agricultural biotechnology is being driven by some of the most powerful multinational companies in the global economy, including such giants as Monsanto and Du Pont. The absence of effective regulatory frameworks and safeguards for monitoring the handling and use of biotechnologies brings into sharp relief the limits of state capacity, while the pace of technological development in the sector far outstrips the ability of legal frameworks to manage its consequences. The politics of aid, trade and redistribution that modern biotechnology has given rise to, amid claims about the ability of genetically modified organisms (GMOs) to feed the world, make it a pressing development issue on the agendas of governments and global institutions. What can these institutions do to manage the technology in a way which benefits the poor? How, in constructing mechanisms of international governance to regulate the social and environmental consequences of modern biotechnology, can they ensure that the food security of the poor is safeguarded?

At first sight, it would seem unreasonable to expect the activities of international institutions to have much consequence for the lives of the rural poor in the developing world. Yet, as donors and academics are increasingly emphasising, global institutions in many ways mediate the relationship between globalisation and poverty, of which food insecurity is one manifestation. Trade rules and environmental regulations that bear directly upon the rights and responsibilities of governments impinging in positive and negative ways upon their "food sovereignty" are now in place. The ability of developing country governments in particular, to make pro-poor policy choices in agriculture is being circumscribed by a combination of rules on agricultural and food trade policy and on intellectual property rights. These rules define the conditions upon which countries can prohibit or restrict the import of certain agricultural products, or promote or access specific technologies in order to address food security needs.

These issues formed the background to a project on 'Globalisation and the International Governance of Modern Biotechnology', some of the findings of which are summarised in this article. The project sought to examine the relationships between, for example, the World Trade Organization (WTO), the Cartagena Protocol on Biosafety (CBP) and other international organisations addressing biotechnology, as well as the interaction between these bodies and national governments in developing countries. It also sought to identify where and how the agribiotech industry is influencing policy processes both at the national and international level. The aim was to identify constraints upon national policy makers in formulating policy on biotechnology that accords with obligations to international organisations and meets the food security needs of poorer farming communities; to explore the role and limitations of national regulation of biotechnology in the context of globalisation and to consider the extent to which international institutions can supplement the ability of governments to promote food security. The focus was on transgenic crop biotechnologies, which have generated most concern about their potential environmental, health and socio-economic impacts. Our interest was in the implications of efforts to regulate these impacts through global regimes on trade, food and the environment on national level efforts in India and Kenya to combat food insecurity. 


\section{Food security: the missing agenda}

Amid the global debate about the pros and cons of biotechnology for the poor, our starting point has been to look at the role of institutions and the relations of power that they embody, in order to understand the extent to which the leading global institutions in the biotech debate are likely to be able to respond to the food security needs of the poor. This emphasis comes amid increasing claims that such institutions are key to harnessing the potential of globalisation to tackle poverty (DFID 2000).

While recognising the potential for these institutions to work for the poor, our work suggests that the institutions of global governance currently active on the issue of biotechnology are failing adequately to address the needs of the poor, at least in terms of their ability to address food security concerns, the area of greatest potential benefit from the technology for the poor. We found evidence of a disconnect between the content and orientation of the international mechanisms that have been developed to "govern" biotechnology and the nature of the policy mechanisms that governments have traditionally made use of and, in some cases continue to deploy, in order to enhance food security. This tension has emerged in a number of contexts.

First, we noted conflicts between the demands of many domestic producers and farmers groups for forms of domestic protection from exposure to foreign markets such as subsidies, and the requirements of the WTO's Agreement on Agriculture for the lifting of quantitative restrictions and removal of some forms of subsidy protection (Dhar and Dey 2002).

Second, we noted the conflict that emerged in the Biosafety Protocol negotiations over whether and how socio-economic considerations would be treated in the Protocol. In the end, language was adopted whose implications are not yet entirely clear, which focuses on socio-economic impacts associated with biodiversity loss (Mackenzie 2003). Broader formulations that might have allowed countries to consider impacts such as the impact on access to affordable food, loss of livelihood and income, or impacts on employment from market displacement, etc. were opposed by GMO-exporting countries (and by most other developed countries) as unjustifiable trade barriers (Stabinsky 2000).

Third, we noted that, though seed sharing and exchange and informal processes of innovation are key to the maintenance of food security in many rural areas, some forms of plant variety protection and intellectual property regimes restrict these types of practices. For these reasons, both India and Kenya initially supported the idea of excluding living and biological materials from patent protection although post-TRIPs (Trade-Related Aspects of Intellectual Property Rights) their ability to do so has been curtailed (Ramakrishna 2003; Odame et al. 2003).

A fourth and more general tension derives from the relationship between diversity and autonomy in national priority-setting around biotechnology issues and the thrust of many international initiatives towards harmonisation of safety regimes and universalisation of risk assessment procedures. This issue arises in relation to questions of patent protection and the role of socio-economic considerations, but is also expressed in the challenge posed to a country's food sovereignty by trade disciplines. While some of the measures described above might be thought to be key for the protection of food security, alongside a raft of measures such as protection for infant seed industries and active discrimination between domestic and foreign food producers, the imperatives of trade liberalisation have been invoked to question and challenge the scope that national governments have to formulate such policies as well as their legal compatibility with global trade accords.

A fifth tension we observed derives from the higher priority given to food safety over food security concerns in the work of bodies such as Codex and the way in which the WTO agreements on Technical Barriers to Trade (TBT) and Sanitary and Phytosanitary Measures (SPS) have been employed to date. A repeated theme has been the relative absence among the institutions of international governance handling biotechnology issues of bodies whose primary mandate is the promotion of food security (Mackenzie 2003). Questions have been asked about the role of bodies such as the Food and Agriculture Organisation (FAO) and the International Fund for Agricultural Development (IFAD), but the 
former is seen by many developing countries to be too uncritical about the role of biotechnology in tackling food security to be a reliable ally and IFAD is generally regarded as too weak, lacking in resources to play an effectual role.

A sixth problem is that the very actors whose activities increasingly impact most directly on the livelihoods of the rural poor are currently those whose operations are least regulated by international law: transnational corporations. One of the greatest threats posed to the supply of affordable seeds tailored to local conditions is the consolidation within the global seed industry and the trend towards mergers and acquisitions (UK Food Group, undated). The dumping of their products on developing country markets is permitted by subsidies to farmers in the North, which continue to be a bone of contention in global trade talks.

Beyond this, the activities of a broader set of international institutions, whose role in this debate was beyond the scope of our study, are also key to food security. In this regard, the activities of the World Bank and International Monetary Fund (IMF) in determining questions of access as well as shaping the markets and institutions that mediate between suppliers of food, public and private and the rural poor, is critical. Alongside these principally economic actors, we also noted the role of organisations such as International Food Policy Research Institute (IFPRI), and the Consultative Group on International Agricultural Research (CGIAR) more generally, in promoting biotechnology as a possible solution to food security. The activities of these bodies may have more of a direct bearing on the research orientation of national agricultural research centres and the incentives and disincentives they face when considering technology options than the global politics of trade described in this article which clearly impact more on globallytraded commercial crops than on innovations intended for local use and consumption. In other words, many of those technological innovations which may make the most direct contribution towards the food security of the poor, tackling crops and traits for which there is high levels of demand from resource poor farmers, may be unaffected by the broader global politics we describe here. However, the vast majority of current agri-biotech developments are not focused on these crops and traits and yet have serious implications for the food security of the poor in positive and negative and direct and indirect ways, and it is these technologies that are the subject of the international regulations that we have explored in this project.

\section{The limits of multilateralism}

Despite the great faith that is placed in multilateral institutions, our work has underscored the need to keep in mind the limits of multilateralism in producing effective outcomes and in overseeing a process that is beneficial to developing countries in particular.

First, a key trend, which emerges from our work, is the ongoing importance of bilateralism in a world of multilateral institutions. This can take a number of forms, but essentially includes various forms of bilateral political pressure from powerful states towards weaker developing countries. This leverage is underpinned by the dependence of developing countries on trade and aid. There have been many reported examples of developing countries subject to strong forms of political pressure to revise their biosafety regulations in line with the interests and concerns of powerful exporting countries. Bolivia, Sri Lanka, Egypt, Croatia and Thailand have all reportedly been subject to bilateral pressures to relax the stringency of their regulatory systems or to retreat from de facto moratoria on the technology's import and development within the country. In the case of China, changes were made to the development of regulations of labelling and import following a high-profile visit from President Bush and a delegation of trade officials (Newell 2003a).

Clearly these pressures have not just been applied to developing countries, as the recent complaint by the USA and others at the WTO against the EU's alleged de facto moratorium on GM crops highlights. But the particular vulnerability of developing countries to the threat of trade action or the withdrawal of much needed aid carries extra significance. Such pressures are also applied within multilateral fora. A number of representatives from developing country delegations recalled "threats", as they described them, from GMO exporters of withdrawals of aid in the absence of them adopting of a more compliant position towards the needs of GMO exporting countries (Newell and Glover 2003). 
In light of the failure of the Cancun talks, we can expect renewed emphasis by the USA and others on seeking market access through bilateral deals on biotechnology and other issues rather than awaiting the resolution of complex conflicts through multilateral means. While larger developing countries may be able to stand up to such pressure, smaller countries inevitably have less leverage to resist the demands of powerful exporters. This state-based lobbying will be backed up, as in the past, by pressure from biotech firms themselves threatening relocation or refusing to invest in a country unless a more accommodating government position is taken (Newell and Glover 2003).

Multilateral fora will continue to be key however, and there remains a need to address the limited nature of participation of developing countries in global policy processes. This results from the process inequities associated with the organisation and nature of multilateral processes. Issues here include the financial resources required to be able to attend negotiations which limits the number of delegates that a country can send, and which in turn constrains the number of meetings, often held simultaneously, at which a country can be represented. Lack of capacity to engage fully in all aspects of international negotiating processes, which culminate in adoption of a "package deal", such as the WTO single undertaking, has meant that a number of developing countries may have only fully appreciated the range and scope of obligations they had agreed to by signing up to the Uruguay Round and the TRIPs Agreement in particular, once they had done so.

Issues of capacity also plague the process of translating global commitments into practice at the national level. There are problems of conflicts over interpretation of agreements and the consistency between different, and potentially competing, bodies of international law. There are also more fundamental issues of capacity to manage the requirements made of countries by international agreements. Hence in the case of intellectual property rights, developing countries have argued that they are not in a position to protect intellectual property rights (IPRs) in the same way as developed countries. The response has been the provision of capacity-building support to patent offices from World Intellectual Property Organisation (WIPO) or WTO. Concerns have been expressed by people working in those patent offices, however, that the "support" and training they receive from bodies such as WIPO and WTO does not reflect national priorities and in some ways pre-judges what their needs will be, especially in the case of countries that have yet to join the WTO. There is concern that capacitybuilding is oriented towards speeding up the registering of patents for foreign companies seeking market access rather than exploring options for designing a patenting system that protects key crops and publicly owned innovations from being patented for exclusive use. In this sense, capacitybuilding efforts could seek to ensure that patent offices and judicial bodies in developing countries understand flexibilities available under TRIPs and implications of different interpretations of key terms, including how such terms were interpreted by developed country patent offices and courts. There are strong arguments to support increased time-frames for TRIPs implementation for all developing countries, not just least-developed countries, in order to craft sui generis options for IPRs relating to plant varieties and biotechnological innovations.

If they are to be implemented, international agreements need to make realistic demands of national regulatory systems. The Cartagena Protocol on Biosafety is centred on an effective system of national import licensing and advance informed agreement that places resource and capacity demands on bureaucracies that they may not be in a position to meet, particularly in developing country settings. There have now been numerous incidents of accidental release and illegal growing and trading in seeds which governments have been unaware of, for example, the illegal sale and growing of Bt cotton in Gujarat state, India (Dhar 2003). The ungovernability of seeds as an object of regulation exposes, once again, the limits of what we can expect multilateral processes to achieve. The informal exchange of GM and non-GM seeds is very difficult to track and monitor. Problems of GM food aid and controlling the use of seeds entering the market as aid, underscore this pattern of ungovernability and help to explain concerns expressed by Zambia, Zimbabwe and Ethiopia regarding the receipt of GM food aid from the USA in particular, and the impact this may have on genetic diversity within their countries 
through leakage and illegal growing. Though this clearly raises issues of capacity, it is not just a problem for developing countries, as instances of unauthorised releases in the UK as well as of corporations not having control of their own products, such as StarLink in the USA, testify. The issue is not just one of capacity, therefore, but of the nature of "genetic pollution" and the difficulties associated with its control, however effective a system of regulation is claimed to be. With regard to implementation and enforcement, particularly where regulatory structures are weak or under-resourced, non-state actors may assume an important role in monitoring. However, in reaching decisions on whether to import particular GMOs, countries may need to take into account their limited capacity to monitor and enforce effective risk management measures.

A further problem associated with the export, through multilateral agencies, of particular approaches to the governance of biotechnology, is that they tend to overlook significant ecological and socio-economic differences within societies, in addition to their political peculiarities, described above. There is a tendency in risk assessment approaches, advocated by bodies such as the OECD (Organization for Economic Cooperation and Development) and supported by industry groups keen to minimise interference in trade (Newell and Glover 2003), to assume that conditions in one country prevail everywhere. By trying to reduce regulatory hurdles and encourage concepts such as substantial equivalence and familiarity, which reduce the need for new testing, risk assessment procedures tailored to the agro-ecological conditions prevailing in different regions of the same country even, may be overlooked. This has implications for food security particularly in countries that are centres of origin or diversity for key crops (such as maize in Mexico) and where smallholder farmers are dependent on local varieties of staple crops (Odame et al. 2003). Not only does the level of socially acceptable risk differ by society, such that global benchmarks are often inappropriate, but the range of tests that a country might want to undertake particularly in settings such as these, where crops that are central to a country's food security may be affected by imports of GMOs, requires a greater degree of flexibility for nationally attuned frameworks for risk assessment than is possible at the moment. While the CBP is ambiguous about the scope for socio-economic assessments, examining the socio-economic implications of potential impacts of GM crops on local varieties and of reduced reliance on local varieties in itself might provide a useful screening mechanism for identifying food security implications.

\section{The "shadow of WTO": international trade rules and biotechnology policy}

A major theme throughout our research has been the pivotal role of the WTO in framing the context within which both national and international institutions are addressing the governance of modern biotechnology, both in terms of regulation and property rights. This emerged in a number of different contexts, and could be said to include both direct and indirect impacts on national and international policy making. Areas of influence include: the impact of WTO rules on national law and policy, through requiring adaptation of national level regulations to comply with WTO disciplines, for example under the TRIPs Agreement; the influence of WTO rules on the negotiation of international agreements, for example the Biosafety Protocol; the bilateralisation or regionalisation of WTO disciplines in free trade agreements; and the impact of the potential for challenge to national health and environmental standards through the WTO dispute settlement system.

Though not unique to biotechnology, the influence of WTO rules over national laws and regulations on matters such as trade in goods, labelling and intellectual property rights is striking. In this respect, the WTO has either directly required, in the case of intellectual property, or has promoted and underpinned, in the case of sanitary and phytosanitary regulation, international harmonisation of standards (Mackenzie 2003). In many respects, the WTO Agreements have imposed a significant legislative burden on developing countries (e.g. Odame et al. 2003; Ramakrishna 2003). For example, the TRIPs Agreement has been instrumental in setting the time-frames and contours of national intellectual property laws, as they relate, in particular, to protection of plant varieties and other living organisms. As countries seek to meet the deadlines for implementation of their obligations under TRIPs, time may not permit full consideration of whether or not new intellectual property laws meet (or do not meet) national needs, priorities and 
interests, including those related to food security. The same problem to some extent applies to the International Union for the Protection of New Varieties of Plans (UPOV) agreement where the Commission on Intellectual Property Rights (CIPR) has noted that it provides a ready made legislative framework, but a disadvantage is that it was designed with the commercialised farming systems of developed countries in mind' (CIPR 2002: 69). The Indian case study in our project showed, however, how a country can undertake a more broad-based consultation and consideration with a view to incorporating a form of farmers' rights into its national plant variety rights legislation, resulting in the adoption of the Protection of Plant Varieties and Farmers Rights Act (PPVFRA) in this case (Seshia 2002).

Notwithstanding the incorporation of provisions on special and differential treatment in the WTO Agreements, the drive to harmonisation and trade liberalisation has failed to accommodate the differentiated capacities and priorities of countries at different stages of development. This is especially problematic in a relatively new area such as biotechnology. While many developing country governments have expressed strong interest in exploring the potential of biotechnology in agriculture, at the same time concerns exist owing to gaps in the understanding of the potential health, environmental and socio-economic impacts of the technology and in the capacity to assess and manage such risks. This is exacerbated by the influence of WTO rules, both in constraining national policy making, and on other international organisations which might otherwise be expected to provide more policy space for governments to address the food security and other socio-economic implications of modern biotechnology.

Despite the adoption of specific international instruments on biosafety, the need for WTO compliance and the threat of challenge under WTO rules may have a "chilling effect" on national safety regulations, and on related legislation such as labelling rules. For example, China's proposed new laws on import regulation and labelling of GMOs were delayed after pressure from the USA and following China's accession to the WTO, which has necessitated extensive review and amendment of national laws (Newell 2003b). Thus, the influence of the WTO also operates indirectly, through trade diplomacy with major trading partners and powers.
The imperatives of trade liberalisation become then the reference point for discussions of issues of biosafety and food security. Increasingly, policy interventions in these areas have to be validated by demonstrating that they do not raise unnecessary or discriminatory barriers to trade. This has serious implications for the national autonomy of governments whose policies on food security and environmental risk are increasingly subject to trade disciplines through agreements such as TRIPs, the SPS and TBT Agreements and the Agreement on Agriculture.

The "shadow of the WTO" is also discernible in the international negotiations themselves, notably in the negotiation of the Biosafety Protocol and in ongoing discussions in the Intergovernmental Committee on the Cartagena Protocol, as well as in the Codex Alimentarius and in the International Plant Protection Convention (IPPC) (Mackenzie 2003). With regard to the IPPC and the Codex, it is notable that certain WTO Agreements have conferred a privileged status upon formally non-binding international guidelines and standards, thus "raising the stakes" of international standard-setting processes (Mackenzie 2003; Victor 2000; Marceau and Trachtman 2002). However, the ability of developing countries to participate in Codex and other standardsetting bodies, and to implement international standards, has been weak, and has only recently begun to be addressed. In addition, the principles of the WTO are increasingly being replicated or reflected in other fora, including the standard-setting bodies themselves (Mackenzie 2003).

Notwithstanding recent movement towards harmonisation of international standards, there remains a degree of unpredictability of outcome with regard to the application of regulatory measures governing GMOs and with regard to potential challenges to such measures. Policy ambiguities and uncertainties, as well as gaps, exist. For example, nine years after the adoption of the TRIPs Agreement, there is continuing uncertainty as to what may be patentable (e.g. plants, plant varieties, animals) and what must be patented (e.g. microorganisms, non-biological processes, etc.); and as to when flexibilities under TRIPs, such as compulsory licensing, might be used (Yamin 2003).

In addition, it is not clear how, to what extent, and which socio-economic considerations might be taken into account in decision making on imports of GMOs (Stabinsky 2000). Some socio-economic 
concerns, which seem likely to be of potential concern to developing countries related to GMOs, may not necessarily fall within the scope of Article 26 of the Biosafety Protocol, which in any event requires countries to act consistently with their other international obligations, including those under the WTO, when taking socio-economic considerations into account in decision making on GMOs. To some extent, these uncertainties might leave space for national regulatory autonomy. But they also leave developing countries open to considerable pressure from GM exporters and environmental activists alike about how they choose to interpret the precautionary principle.

One mechanism for resolving conflicts is of course the WTO's dispute settlement system. This has been used in relation to TRIPs, for example in litigation initiated by the USA against Argentina concerning patentability of micro-organisms (Yamin 2003). The approach of the Appellate Body, in particular, in addressing Article XX of the General Agreement on Tariffs and Trade (GATT) and the provisions of the Agreement on the Application of Sanitary and Phytosanitary Measures, indicates that there is scope for a country to justify restrictions on imports of GMOs on environmental and health grounds. However, since the conclusion of the Uruguay Round and the formalisation of the role of dispute settlement in the WTO, concerns have been expressed that the dispute settlement system, which is designed to underpin the rule-based system, does not itself provide a level playing field. First, the process of dispute settlement may be too costly in terms of human and financial resources required. Second, the most effective remedies available under the WTO are bilateral, such as the suspension of concessions including crossretaliation. Yet these remedies are less appropriate for developing countries, with their relative lack of trading power. The lack of transparency in dispute settlement proceedings, both as regards other WTO members and as regards civil society has provoked disquiet. And concerns about the WTO dispute settlement system have also been expressed regarding the role of businesses in prompting their national governments to mount a challenge in the WTO to other countries' measures which restrict market access for biotech products. While the Dispute Settlement Understanding is under review, it remains to be seen to what extent reforms will address the concerns of developing countries.
The disciplines imposed by the WTO and the frameworks promoted through instruments such as the Protocol and the Codex highlight competing principles of harmonisation, on the one hand, and diversity on the other. This tension is reflected at the national and international level, and operates between different international institutions, for example the Convention on Biological Diversity with its emphasis on national circumstances and priorities compared with the drive for harmonisation and international minimum standards in TRIPs. The "single undertaking" principle of the WTO, notwithstanding the accommodation of the principle of special and differential treatment for developing countries, restricts the policy space available to developing countries (and indeed to other countries) to address needs, priorities and preferences in relation to agricultural biotechnology. In this regard, developing countries are forced to make trade-offs as they develop national policy, and also as they formulate negotiating positions for the various international fora addressing GMOs. Thus, while most developing countries supported a strong Biosafety Protocol, incorporating socioeconomic considerations, and taking precedence over relevant WTO obligations, in the WTO itself, they have been wary of efforts to address trade and environment issues, including the link between the WTO and multilateral environmental agreements, for fear that such developments might further hamper access of their goods to developed country markets. The principle and operationalisation of special and differential treatment in the WTO meanwhile is yet to be clarified in a meaningful way and remains under negotiation.

\section{Conclusion}

Many of the problems we have described in this article are not unique to biotechnology, even if they take on more critical dimensions in the context of the food security of the poor. There have also been some efforts to address them. But despite numerous international initiatives devoted to avoidance of duplication, and to enhancing synergy and interlinkages between international institutions, it is not clear that these are resulting in real improvements in the international governance of modern biotechnology. There have been improvements in information exchange and cross-representation among international organisations and a gradual increase in the recognition of the range of interests 
and actors that need to be brought into the debate. There is still a long way to go, however, before pivotal decision-making fora can be said to have integrated food security concerns into their current and future programmes. Creating new institutions specifically to address modern biotechnology is unlikely to be an effective solution, however. While an initiative along the lines of the Intergovernmental Panel on Climate Change has been mooted by the OECD, our research suggests a series of location, environment and context-specific interventions are more likely to be effective.

Faced with constraints imposed by the international institutions described above, one possible response is forum shifting: seeking to move the debate, or elements of it, into a more responsive international forum. Rather than forum-shopping for more responsive, inclusive institutions that are weak within the overall process, however, it is important to promote the participation and interests of developing countries within the WTO itself. Looking to institutions such as UNCTAD, that are both active on the biotech issue and seemingly and traditionally more responsive to the concerns of developing countries, may be appealing. But there are questions about the ability of such organisations to respond to developing country concerns on the biotech issue; whether they have the capacity to do what is expected of them. For reasons of lack of funding and breadth of mandate, a body such as UNCTAD may not be well placed to shift the regulatory agendas of bodies such as the WTO.

If we accept that food security should not be constrained by prevailing trade disciplines, then we cannot ignore the role of bodies such as the WTO in this debate. There are sound social and economic reasons why controls on imports are sometimes necessary to protect fragile markets and vulnerable groups from the consequences of full market exposure, especially where environmental, health and socio-economic impacts are uncertain and potentially damaging. Forcing countries to accept GM products through resort to trade and aid pressures runs counter to the need for countries to consider whether they want biotechnology, having assessed its implications, and if so, under what conditions and with what safeguards in place. At the moment, the democratic space in which to make that assessment is being closed down. Ironically, the net effect may be to generate resentment towards an imposed technology, without adequately considering its potential advantages.

In turn, this requires international institutions to be more flexible in the time-frames within which they allow countries to set up biosafety frameworks, for example, to allow time for fuller forms of consultation and public participation. This is important for anticipating negative impacts as well as the positive potential of particular biotechnology developments for the food security of the poor. However, for such processes to be legitimate and for groups to consider engaging in them worthwhile, they have to make a difference. If governments' hands are to some extent tied by their existing international obligations and certain policy options are already off the agenda, it will be difficult to persuade citizen groups to engage in exercises in public consultation and participation if they feel the government cannot, ultimately, act on their demands.

Harmonised approaches to regulation and risk assessment run the danger of closing down public spaces for citizens to debate which biotechnology future they want and why, and of reducing the scope for countries and groups within countries to prioritise the role of biotechnology in tackling food insecurity in their own (different) ways. Many capacity-building programmes such as those overseen by UNEP-Global Environment Facility (GEF) have focused on the creation of toolkits and clearly sequenced policy processes that should be undertaken in the design of a country's national biosafety framework. They have strongly emphasised government control of the process, the importance of experts in "informing" the public about what they need to know about biotechnology and biosafety and the need to narrow public involvement to discussion of issues on terms set by the Protocol. Such an approach, reflecting clear bureaucratic imperatives for standard forms of policy implementation, is unlikely to be conducive to the construction of more open and inclusive society-owned spaces for policy dialogue on issues of national priority including food security.

But increased levels of public participation will not be sufficient to shift the debate towards a more serious treatment of food security concerns. In the absence of efforts to redress the power inequalities that keep these issues off the policy agenda and concentrate power in the hands of a policy and commercial elite, such measures will have a negligible overall effect. New mechanisms to 
enhance the accountability of the private sector are therefore required. These may include enhancing the use of competition law to prevent monopolistic practices in the agricultural biotechnology and seed sectors. The mergers of AstraZeneca and Novartis to form Syngenta and of Aventis CropScience and Bayer to form Bayer CropScience illustrate the propensity for corporate concentration in the biotech sector and the implications this has for farmer choice. For example, Monsanto has increased its market share of the Brazilian maize market from zero to 60 per cent in just two years, with the result that only one Brazilian company now remains in that sector with a market share of only 5 per cent (Nuffield Council on BioEthics 2003). We may need to consider restricting the scope of claims for commercial confidentiality where these limit public access to information and participation in decision making. Restricting the application of broad patents would also represent a timely intervention. The recent Nuffield Council on BioEthics report recommends that: 'owners of patented technology should be encouraged to licence their technology non-exclusively, that patent offices should avoid the granting of overly broad patents and that the impact of patents on access to germplasm should be monitored' (Nuffield Council on BioEthics 2003).

Getting such controversial issues onto the agenda of the WTO will clearly not be easy. Yet, the recent breakdown of the world trade talks in Cancun may suggest the emergence of a political dynamic in the global politics of trade in which developing countries are willing and able to exercise a veto over developments they consider to be against their interests. China's membership of the WTO, mounting frustration at the lack of progress in delivering a "development round" and the ongoing critical spotlight on the WTO's activities provided by protests from elements within civil society have contributed to this change of events. Such developments may represent the best hope yet that developing countries can force concessions from the developed world across a range of issue areas.

Biotechnology also goes to the heart of fundamental debates about how far trade rules should be allowed to override international rules that restrict trade for the purpose of social or environmental protection. Such concerns are expressed in the title of this article, 'Whose rules rule?', taken from the trade campaign of the development NGO, the World Development Movement. This raises key democratic questions about the respective rights and responsibilities of states and international institutions; how much autonomy can legitimately be preserved for development policy choices in the face of universalising rules? Do the investment rights of a company trump the rights of a government to determine which forms of investment it considers to be good for development? The contest over these issues forms the battleground on which the future of biotechnology will be fought out.

\section{Notes}

* This study draws on work done as part of the project 
'Globalisation and the International Governance of Modern Biotechnology', financed by a research grant from the UK Department for International Development (DFID). DFID supports policies, programmes and projects to promote international development and provided funds for this study as part of that objective, but the views and opinions expressed are those of the authors alone.

\section{References}

CIPR, 2002, Integrating Intellectual Property Rights and Development Policy, London: Commission on Intellectual Property Rights

Dhar, B., 2003, 'Regulating biotechnology in I $\mathrm{n} \quad \mathrm{d} \quad \mathrm{i}$ a , , www.gapresearch.org/governance/RISIndiafin al.pdf (accessed October 2003)

Dhar, B. and Dey, S., 2002, 'Global Trade and Agriculture: a Review of the WTO Agreement on Agriculture', in P. Newell, S. Rai and A. Scott (eds), Development and the Challenge of Globalization, London: ITDG Press

DFID, 2000, Making Globalisation Work for the Poor, London: Department for International Development

Mackenzie, R., 2003, 'The international regulation of modern biotechnology', Yearbook of International Environmental Law, Vol 13, forthcoming

Marceau, P. and Trachtman, G., 2002, 'The technical barriers to trade agreement, the sanitary and phytosanitary measures agreement, and the general agreement on tariffs and trade: a map of the World Trade Organization Law of Domestic Regulation of Goods', Journal of World Trade, Vol 36 No 5: 811-81

Newell, P., 2003a, 'Domesticating global biotech policy: comparing China and India', IDS
Working Paper 206, Brighton: Institute of Development Studies

Newell, P., 2003b, 'Globalisation and the governance of biotechnology', Global Environmental Politics, Vol 3 No 2: 56-72

Newell, P. and Glover, D., 2003, 'Business and biotechnology: regulation and politics of influence', IDS Working Paper 192, Brighton: Institute of Development Studies

Nuffield Council on BioEthics, 2003, The Use of Genetically-Modified Crops in Developing Countries, London: Nuffield Council on BioEthics

Odame, H., Kameri-Mbote, P. and Wafula, D., 2003, 'Globalisation and the international governance of modern biotechnology: implications for food security in Kenya', IDS Working Paper 199, Brighton: Institute of Development Studies

Ramakrishna, T., 2003, The Development of the IPR Regime in India with Reference to Agricultural Biotechnology, www.gapresearch.org/governance/ biotech.html, (accessed November 2003)

Seshia, S., 2002, "Plant variety protection and farmers' rights: law-making and the cultivation of varietal control', Economic and Political Weekly, 6 July: 2741-7

Stabinsky, D., 2000, 'Bringing social analysis into a multilateral environmental agreement: social impact assessment and the biosafety protocol', Journal of Environment and Development, Vol 9 No 3: 260-83

UK Food Group, (undated), Working Together for Global Food Security, London: UK Food Group

Victor, D., 2000, 'The sanitary and phytosanitary agreement of the World Trade Organization: an assessment after five years', New York University Journal of International Law and Politics, Vol 32 No 4: 865-937

Yamin, F., 2003, 'Intellectual property rights, biotechnology and food security', IDS Working Paper 203, Brighton: Institute of Development Studies 